\title{
Influência do Fotoperíodo e da Temperatura na Intensidade de Doença Causada por Fusarium graminearum em Egeria densa e $E$. najas $^{1}$
}

\author{
Carlos R. Borges Neto ${ }^{1}$, Cláudia Q. Gorgati ${ }^{2}$ \& Robinson A. Pitelli ${ }^{1}$ \\ ${ }^{1}$ Departamento de Biologia Aplicada à Agropecuária, ${ }^{2}$ Departamento de Engenharia Rural, Faculdade de \\ Ciências Agrárias e Veterinárias de Jaboticabal, Universidade Estadual Paulista, Via de Acesso Prof. Paulo Donato \\ Castellane, s/no CEP 14884-900, Jaboticabal, SP
}

(Aceito para publicação em 09/03/2004)

Autor para correspondência: Carlos R. Borges Neto.

BORGES NETO, C.R., GORGATI, C.Q. \& PITELLI, R.A. Influência do fotoperíodo e da temperatura na intensidade de doença causada por Fusarium graminearum em Egeria densa e E. najas. Fitopatologia Brasileira 29:252-258. 2004.

\section{RESUMO}

Um isolado de Fusarium graminearum vem sendo estudado na UNESP, Campus de Jaboticabal, como agente de controle biológico de Egeria densa e E. najas, macrófitas aquáticas submersas, muito problemáticas em reservatórios de hidrelétricas. O presente trabalho teve por objetivo estudar os efeitos do fotoperíodo $\left(0 ; 4 ; 8\right.$ e $12 \mathrm{~h}$ diárias de luz) e da temperatura $\left(15^{\circ} \mathrm{C}\right.$, $20^{\circ} \mathrm{C}, 25^{\circ} \mathrm{C}, 30^{\circ} \mathrm{C}$ e $35^{\circ} \mathrm{C}$ ) no controle destas plantas em condições de laboratório. A cada dois dias foram avaliados os sintomas nas plantas inoculadas com $F$. graminearum, atribuindo-se notas de severidade de doença, por um período de oito dias após a inoculação. Também foi avaliado o crescimento das plantas por meio do ganho de massa fresca, expresso em porcentagem. A maior severidade de doença foi observada quando ambas as espécies foram mantidas no escuro e a menor em fotoperíodo de $12 \mathrm{~h}$. A temperatura de $30^{\circ} \mathrm{C}$ proporcionou maior severidade de doença em ambas espécies. Egeria densa apresentou maior produção de massa fresca no regime de $12 \mathrm{~h}$ de luz e de temperaturas abaixo de $25^{\circ} \mathrm{C}$ e menor produção no regime de escuro total e nas temperaturas de $30{ }^{\circ} \mathrm{C}$ e $35^{\circ} \mathrm{C}$. Egeria najas apresentou menor produção de massa fresca no regime de escuro total e nas temperaturas de $25^{\circ} \mathrm{C}$ a $35^{\circ} \mathrm{C}$.

Palavras-chave adicionais: biocontrole, plantas aquáticas, fatores abióticos.

\section{ABSTRACT}

Effects of photoperiod and temperature in the development of disease caused Fusarium graminearum on Egeria densa and $E$. najas

A very promising Fusarium graminearum isolate was evaluated as a potential biocontrol agent for two important submerged aquatic weeds, Egeria densa and E. najas. In previous studies, the fungus showed high control of the species and satisfactory specificity. However, under some conditions, the results were unstable, probably due to abiotic factors affecting the pathogenesis. In order to evaluate the influences of the photoperiod $(0 ; 4 ; 8$ and 12 daily hours of light) and temperature $\left(15^{\circ} \mathrm{C}, 20^{\circ} \mathrm{C}, 25^{\circ} \mathrm{C}, 30^{\circ} \mathrm{C}\right.$ and $\left.35^{\circ} \mathrm{C}\right)$, studies were carried-out under laboratory conditions in completely randomized plots. The photoperiod effects were evaluated under $25^{\circ} \mathrm{C}$ and $\mathrm{pH}$ 7,0 . The temperature conditions were evaluated after less than $12 \mathrm{~h}$ of photoperiod and $\mathrm{pH} 7,0$. The disease severity was evaluated through a note scale and fresh weight variation. The major severity notes were observed as the photoperiod decreased, especially when less than $8 \mathrm{~h}$, and as the temperature increased, especially above 25 ${ }^{\circ} \mathrm{C}$. There were differences in the plants response to the abiotic factors and the disease development. Egeria densa was more damaged by the fungus in high temperatures as compared to E. najas. Egeria densa was more sensitive to the photoperiod.

\section{INTRODUÇÃO}

A eutrofização promovida pelo enriquecimento das águas com esgotos urbanos, industriais e pelas atividades agrícolas provoca alterações físico-químicas que proporcionam condições para a instalação e crescimento da vegetação aquática. Estas alterações freqüentemente proporcionam a deterioração da qualidade da água. Neste processo, algumas populações de macrófitas são favorecidas em detrimento de outras (Correl \& Correl, 1975). O aumento

\footnotetext{
${ }^{1}$ Parte da tese de doutorado do primeiro autor. Faculdade de Ciências Agrárias e Veterinárias, Jaboticabal, SP. (2003). Parcialmente financiada pela CAPES.
}

de problemas com algumas plantas daninhas aquáticas em reservatórios e lagos (Boyd, 1970; Steward, 1970; Rogers \& Davis, 1972), como o aguapé, Eichhornia crassipes (Mart) Solms, a Pistia stratiotes L. e plantas do gênero Salvinia é atribuído à eutrofização. Em algumas situações, a coluna d'água é oligotrófica ou distrófica e o sedimento é eutrófico, proporcionando condições de transparência da água e de equilíbrio de formas dos nutrientes, que são adequados para assegurar profuso crescimento de macrófitas submersas como Egeria densa Planch. e E. najas Planch., membros da família Hydrocharitaceae (Lorenzi, 2000). Esta condição ocorre em alguns reservatórios brasileiros proporcionando alguns problemas para os usos múltiplos da água e do corpo hídrico 
Influência do fotoperíodo e da temperatura na intensidade de doença...

e, especialmente, para a geração de energia elétrica. São exemplos: os reservatórios de Jupiá e Três Irmãos da Companhia Energética de São Paulo (CESP), o reservatório de Paulo Afonso da Companhia Hidrelétrica do São Francisco (CHESF) e o Reservatório de Santana (Piraí, RJ) da Companhia Light Serviços de Eletricidade. O impacto econômico do controle destas plantas é bastante alto, resultando em custos estimados da ordem de US\$ 1,0 milhão por mês na estação chuvosa, apenas no reservatório de Jupiá (Tanaka, 1998).

As populações de plantas aquáticas submersas são difíceis de manejar ou controlar. O hábito perene de crescimento, a profundidade de colonização, a facilidade de propagação por segmentos de plantas e o próprio ambiente aquático, levando a diluição de agentes de controle são grandes problemas a serem enfrentados. No entanto, o hábito perene e a formação de grandes colonizações, as tornam alvos ideais para a adoção de medidas de controle biológico (Shearer, 1996). Este mesmo autor destaca o controle biológico como a medida mais viável para este tipo de vegetação. Segundo Blackburn et al. (1971), o controle biológico não é uma prática nova e constitui um meio de controlar plantas daninhas aquáticas em áreas onde o uso de práticas químicas e/ou mecânicas é arriscado ou de custo proibitivo.

Pouco se conhece sobre o efeito de agentes fitopatogênicos em plantas aquáticas e não há expressivo conhecimento de microflora associada às espécies em questão. O biocontrole de $E$. densa está sendo investigado em algumas partes do mundo, utilizando-se peixes, moluscos e fungos (Anderson, 1998), sendo considerado efetivo, com adequações ao tipo de habitat, além do baixo custo e do reduzido impacto ambiental. No Brasil, levantamentos sistemáticos de inimigos naturais de ambas as espécies foram efetuados em 1995 em regiões do Pantanal Mato-grossense e nos Rios Paraná e Tietê, pela equipe de controle biológico de plantas daninhas da Faculdade de Ciências Agrárias e Veterinárias da UNESP (Nachtigal, 2000). Com base em observações do referido autor, efetuadas no curso desses levantamentos, a estratégia inundativa de controle biológico foi considerada a mais adequada, uma vez que existiam poucas evidências para ocorrências de epidemias em condições naturais.

Dentre os organismos selecionados, destacou-se um isolado de Fusarium graminearum Schwabe considerado altamente promissor, por proporcionar elevados danos às duas macrófitas, com suficiente seletividade (Nachtigal, 2000). Este fungo é oriundo da Micoteca da Universidade Federal Rural de Pernambuco (UFRPE) e vem sendo intensivamente estudado como agente de controle biológico pela estratégia inundativa (Nachtigal, 2000; Mendes, 2002).

$\mathrm{O}$ presente trabalho faz parte desta pesquisa global e visa estudar as influências das condições abióticas, como fotoperíodo e temperatura na intensidade de doença causada pelo fungo sobre as duas espécies de macrófitas. Estes conhecimentos são de fundamental importância para se estabelecer as condições ótimas de infecção e do real potencial do agente de biocontrole.

\section{MATERIAL E MÉTODOS}

O isolado de $F$. graminearum utilizado foi cedido pelo Laboratório de Fitopatologia da UFRPE. Quando de sua entrada no Banco de Germoplasma de Fungos Fitopatogênicos do Laboratório de Controle Biológico de Plantas Daninhas "Prof. Dr. Giorgio de Marines", da FCAV - UNESP, recebeu o código FCAV\#940. As colônias foram mantidas em tubos de ensaio contendo o meio BDA, sob refrigeração $\left(4^{\circ} \mathrm{C}\right)$. Foram efetuadas transferências de colônias para placa de Petri contendo o mesmo meio. A patogenicidade do isolado foi assegurada por meio de inoculações periódicas nas plantas hospedeiras e recuperação de colônias em meio de cultura.

Para obtenção do inóculo, o fungo foi cultivado em grãos de arroz (Oryza sativa L.), conforme descrito por Nachtigal (2000), a saber: 200 g de arroz-parboilizado, com grãos longos (Uncle Ben's ${ }^{\circledR}$ ), misturados com $120 \mathrm{ml}$ de água destilada em frascos Erlemmeyers com capacidade de 1.000 $\mathrm{ml}$. Este conjunto foi autoclavado por $20 \mathrm{~min}$ a $120{ }^{\circ} \mathrm{C} \mathrm{e}$ pressão de $1 \mathrm{~atm}$. Após a autoclavagem e resfriamento, três discos de micélio-ágar, retirados das margens de colônias cultivadas por 14 dias, a $25^{\circ} \mathrm{C}$ e fotoperíodo de $12 \mathrm{~h}$ diárias de luz, foram transferidos para cada frasco.

Após 14 dias de incubação em estufa para BOD, a 25 ${ }^{\circ} \mathrm{C}$ e fotoperíodo de $12 \mathrm{~h}$ diárias de luz, procedeu-se a transferência do conteúdo dos frascos para bandejas $(32 \mathrm{~cm}$ de comprimento x $23 \mathrm{~cm}$ de largura $\mathrm{x} 4 \mathrm{~cm}$ de altura) revestidas com papel alumínio. As bandejas permaneceram por sete dias dentro de câmara apropriada (fotoperíodo de $12 \mathrm{~h}$ diárias de luz, $25 \pm 2{ }^{\circ} \mathrm{C}$, com umidade do ar variando de 50 a $65 \%$ ) com circulação forçada de ar para secagem.

Após a secagem, os substratos colonizados foram moídos em moinho de facas (Marconi, MA 340) e as partículas resultantes, constituídas de micélio e substrato, foram separadas quanto a granulometria, utilizando-se apenas as menores que $0,5 \mathrm{~mm}$. Tais partículas, com densidade de $10 \mathrm{~g} / \mathrm{cm}^{3}$, foram armazenadas a $4{ }^{\circ} \mathrm{C}$, em refrigerador.

Foram coletadas plantas das duas espécies (Egeria densa e E. najas) no Reservatório da Usina Hidrelétrica de Três Irmãos, localizada no rio Tietê (20³9' S; 51 $\left.{ }^{\circ} 18^{\prime} \mathrm{W}\right)$, e Souza Dias, localizada no rio Paraná, em Jupiá - SP (24\%48'S; $\left.51^{\circ} 18^{\prime} \mathrm{W}\right)$, para utilização nos experimentos. Foram realizadas coletas periódicas de propágulos de acordo com a necessidade de plantas. Utilizaram-se ponteiros medindo $8 \mathrm{~cm}$ de comprimento das plantas coletadas.

Os ponteiros de cada espécie tiveram a massa fresca determinada, individualmente, após remoção do excesso de água da superfície das folhas por contato em papel absorvente. Os ponteiros foram transferidos para tubos de ensaio com 2,5 $\mathrm{cm}$ de diâmetro e $20 \mathrm{~cm}$ de comprimento. As plantas foram cultivadas em solução nutritiva de Clark modificada, com 1/5 da força iônica (Clark, 1975). Para a inoculação, 0,7 g de inóculo de F. graminearum foi suspensa em um litro de solução de Clark. Alíquotas de $50 \mathrm{ml}$ desta suspensão foram colocadas em tubos de ensaio onde as plantas foram submersas e tiveram contato com o agente de controle biológico em suspensão. 
C.R. Borges Neto et al.

Nas testemunhas, os procedimentos adotados foram os mesmos, mas foram utilizados apenas grãos de arroz moídos, sem colonização pelo fungo. Após a inoculação as plantas foram acondicionadas em incubadoras para BOD.

No ensaio onde foram estudados os efeitos do fotoperíodo, as plantas, após a inoculação, foram mantidas numa temperatura de $25 \pm 1{ }^{\circ} \mathrm{C}$ e pH 7,0, com variação nos períodos de luz de $0 ; 4 ; 8$ e 12 h diárias.

No ensaio onde se avaliaram os efeitos da temperatura de incubação, o fotoperíodo foi mantido em $12 \mathrm{~h}$ diárias e com $\mathrm{pH} \mathrm{7,0.} \mathrm{As} \mathrm{plantas} \mathrm{inoculadas} \mathrm{foram} \mathrm{submetidas} \mathrm{às}$ temperaturas de $15^{\circ} \mathrm{C}, 20^{\circ} \mathrm{C}, 25^{\circ} \mathrm{C}, 30^{\circ} \mathrm{C}$ e $35^{\circ} \mathrm{C}$.

As avaliações dos sintomas foram realizadas a cada dois dias, até o oitavo dia após a inoculação, com o auxílio de escala de notas (Tabela 1) modificada de Nachtigal (2000). A partir das notas foram calculados os Índices de Infecção, que transformam os dados adimensionais em porcentagem de área foliar com sintomas, utilizando a fórmula proposta por Mckinney (1923):

$\Sigma$ (grau de escala $\mathrm{x}$ freqüência) $\mathrm{x} 100$

Índice de infecção $=\frac{}{\text { (Número total de unidades } \mathrm{x} \text { grau máximo da escala) }}$

A variação da massa fresca da planta, antes e depois da inoculação, também foi avaliada.

Para todos os ensaios, o delineamento experimental adotado foi o de blocos ao acaso com três repetições. Todos os ensaios foram repetidos três vezes no tempo, constituindo os blocos do delineamento.Cada tratamento era constituído de cinco tubos de ensaio e foi utilizada a média das notas e da porcentagem de massa fresca obtidas nas avaliações para constituir o dado de cada parcela experimental. Para as análises estatísticas, os dados de porcentagem de ganho de massa fresca foram transformados em arc-seno $\sqrt{\mathrm{x} / 100}$.

Os dados de severidade de doença, nos ensaios de efeitos de fotoperíodos e temperaturas, foram submetidos à análise não linear utilizando-se a equação de Boltzmann:

$$
Y=\frac{\mathrm{A}_{1}-\mathrm{A}_{2-}}{1+e^{\left(\mathrm{x}-\mathrm{x}_{0}\right) / \mathrm{dx}}}+A_{2}
$$

Onde $\mathrm{A}_{1}=$ ponto de mínimo da curva, $\mathrm{A}_{2}=$ ponto de máximo da curva, $x_{0}=$ centro, $d x=$ constante de tempo. As curvas de tendência foram obtidas utilizando-se o programa Origin $\AA 6.0$.

\section{RESULTADOS E DISCUSSÃO}

\section{Severidade de doença}

Fotoperíodo: A severidade de doença apresentou um crescimento maior, do segundo ao oitavo dia após a inoculação, em plantas de E. densa, nos fotoperíodos de 0 e 4 h (Figura 1 - I e II). Já na espécie E. najas a tendência de severidade crescente é observada mais nitidamente no fotoperíodo de $0 \mathrm{~h}$ (Figura 1 - I).

Os maiores danos, expressos em porcentagem de área
TABELA 1 - Escala de notas adotadas nas avaliações de sintomas provocados por Fusarium graminearum, isolado FCAV\#940, em plantas de Egeria densa e E. najas, modificada de Nachtigal (2000)

\begin{tabular}{cl}
\hline \hline Nota & Descrição \\
\hline 0 & Sem sintomas \\
1 & Clorose aparente não superior a $5 \%$ do tamanho da brotação \\
2 & $\begin{array}{l}\text { Amarelecimento foliar visível na porção basal ou,eventual- } \\
\text { mente, na porção superior, não afetando mais de 20\% do } \\
\text { tamanho da brotação }\end{array}$ \\
3 & $\begin{array}{l}\text { Amarelecimento afetando os tecidos a té a porção mediana } \\
\text { ou terço superior das brotações }\end{array}$ \\
4 & $\begin{array}{l}\text { Amarelecimento do caule e de mais de } 80 \% \text { da área foliar; } \\
\text { flacidez dos tecidos vegetais e, eventualmente, abscisão dos } \\
\text { segmentos terminais }\end{array}$ \\
& $\begin{array}{l}\text { Amarelecimento generalizado com completa desintegração } \\
\text { dos tecidos vegetais }\end{array}$ \\
\hline
\end{tabular}

foliar com sintomas, provocados pela ação de $F$. graminearum em E. densa e E. najas foram obtidos quando ambas as espécies foram mantidas no escuro (Figura 1 - I), sendo o menor para o fotoperíodo de $12 \mathrm{~h}$ (Figura 1 - IV). As diferenças entre os tratamentos foram significativas para a espécie $E$. najas, para $E$. densa, apenas os tratamentos com fotoperíodo 0 (Figura 1 - I) e 12 h (Figura 1 - IV) diferiram estatisticamente. Nos tratamentos com fotoperíodo 0 e $4 \mathrm{~h}$ (Figuras 1 - I e II) as curvas de progresso de doença foram semelhantes para ambas as espécies e a porcentagem de área foliar com sintoma ficou em torno de $80 \%$ no oitavo dia após a inoculação.

As curvas de progresso da doença causada por $F$. graminearum em plantas de E. densa e E. najas (Figura 1) mostram que no fotoperíodo de $12 \mathrm{~h}$ de luz (Figura 1 - IV), para ambas as espécies, a severidade de doença foi, praticamente, constante e menor que nos demais tratamentos, em termos absolutos. No fotoperíodo de $8 \mathrm{~h}$ (Figura 1 - III), as curvas de progresso da doença são semelhantes às dos fotoperíodo de $12 \mathrm{~h}$, contudo, com um incremento de aproximadamente $10 \%$ de área foliar com sintomas. Nestes dois tratamentos podemos observar, também, uma diferença de, aproximadamente, $15 \%$ de área foliar com sintomas entre as espécies E. densa e E. najas (Figuras 1 - III e IV).

Os resultados mostram a importância do período luminoso para o crescimento das plantas. Os resultados obtidos são de grande importância para escolha da melhor época do ano para intensificar o controle destas espécies invasoras levando em consideração o comprimento dos dias e noites. A maior intensidade de sintomas em menores períodos de luz pode estar relacionado às situações transitórias de oxigenação, concentração de $\mathrm{CO}_{2}$ e pH da água ou à debilidade da planta. Pesquisas posteriores deverão ser desenvolvidas para esclarecer este comportamento.

Temperatura: Ambas as espécies, quando inoculadas com F. graminearum, apresentaram aumento de intensidade de sintomas com o aumento progressivo da temperatura (Figura 
Influência do fotoperíodo e da temperatura na intensidade de doença...
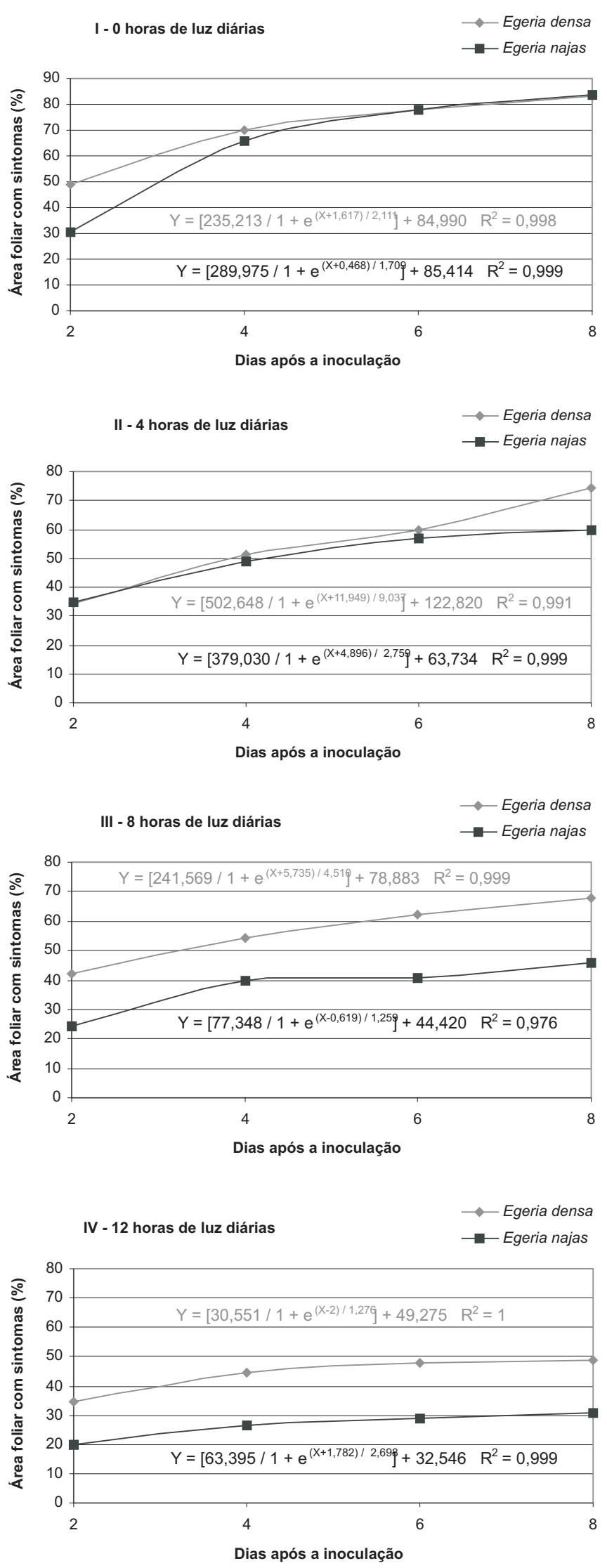

FIG. 1 - Curvas de progresso da doença causada por Fusarium graminearum em plantas de Egeria densa e de Egeria najas em fotoperíodo de 0 h (I), 4 h (II), 8 h (III) e 12 h (IV) diárias de luz.
2). Egeria densa parece ser mais sensível do que E. najas, em relação ao fator temperatura, pois foi observado que o simples fato de incubá-la à temperatura de $35^{\circ} \mathrm{C}$, sem a presença do fungo, ocasionou a degradação dos tecidos, este comportamento, também, havia sido observado por Nachtigal (2000).

Nas condições de temperaturas de $15^{\circ} \mathrm{C}$ (Figura 2 - I) e $20{ }^{\circ} \mathrm{C}$ (Figura 2 - II), para ambas as espécies, foram observadas as menores severidades de doença, sendo que na temperatura de $20{ }^{\circ} \mathrm{C}$ (Figura 2 - II) houve um aumento expressivo na área foliar com sintomas, do segundo ao quarto dia após a inoculação para a espécie $E$. densa, enquanto que para a espécie $E$. najas a porcentagem de área foliar com sintomas permaneceu, praticamente, constante durante o período de avaliação (Figura 2 - II).

As curvas de progresso da doença causada por $F$. graminearum em plantas de $E$. densa e $E$. najas à temperatura de $25{ }^{\circ} \mathrm{C}$ (Figura 2 - III), são semelhantes, sendo que a severidade de doença não alcança $60 \%$ da área foliar com sintomas da doença.

No tratamento com temperatura de $30^{\circ} \mathrm{C}$, a curva de tendência para a espécie $E$. densa (Figura 2 - IV), mostra um maior incremento de severidade de doença a partir do quarto dia de avaliação, atingindo $80 \%$ da área foliar para ambas as espécies. A sensibilidade de $E$. densa a temperaturas mais altas $\left(30^{\circ} \mathrm{C}\right.$ e $\left.35^{\circ} \mathrm{C}\right)$ teve influência direta na curva de progresso de doença quando comparadas às curvas para a espécie $E$. najas (Figura 2 - IV e V), mostrando que o fator temperatura pode potencializar a ação do bioherbicida nas condições que o experimento foi conduzido.

$\mathrm{O}$ fator temperatura aliado ao fotoperíodo podem em condições de reservatórios melhorar a performance do bioherbicida promovendo um controle satisfatório das espécies E. densa e E. najas

\section{Ganho de matéria fresca}

Fotoperíodo: As plantas de E. densa apresentaram maior produção de massa fresca no regime de $12 \mathrm{~h}$ de luz e menor produção nos regimes de escuro total e $4 \mathrm{~h}$ de luz (Figura 3 I). As plantas de E. najas não apresentaram produção de massa fresca nos tratamentos de 0 e de $4 \mathrm{~h}$ de luz, diferindo estatisticamente das demais condições de fotoperíodo (Figura 3 - II). Com relação às testemunhas das duas espécies estudadas verificou-se em todos os tratamentos que estas apresentaram ganho de massa fresca superior às plantas inoculadas, sendo que os maiores ganhos (aproximadamente $45 \%$ ) foram obtidos no fotoperíodo de $12 \mathrm{~h}$ (Figura 3 - I e II). Os resultados mostram a importância do período luminoso para o crescimento das plantas. A maior intensidade de sintomas em menores períodos de luz pode estar relacionado às situações transitórias de oxigenação, concentração de $\mathrm{CO}_{2}$ e pH da água, atividade fotossintética ou à debilidade da planta devido a alterações metabólicas. De modo geral, a severidade de doença é inversamente proporcional à capacidade da planta crescer vegetativamente. Os fotoperíodos de 8 e 12 h de luz proporcionaram melhores condições de produção de matéria 

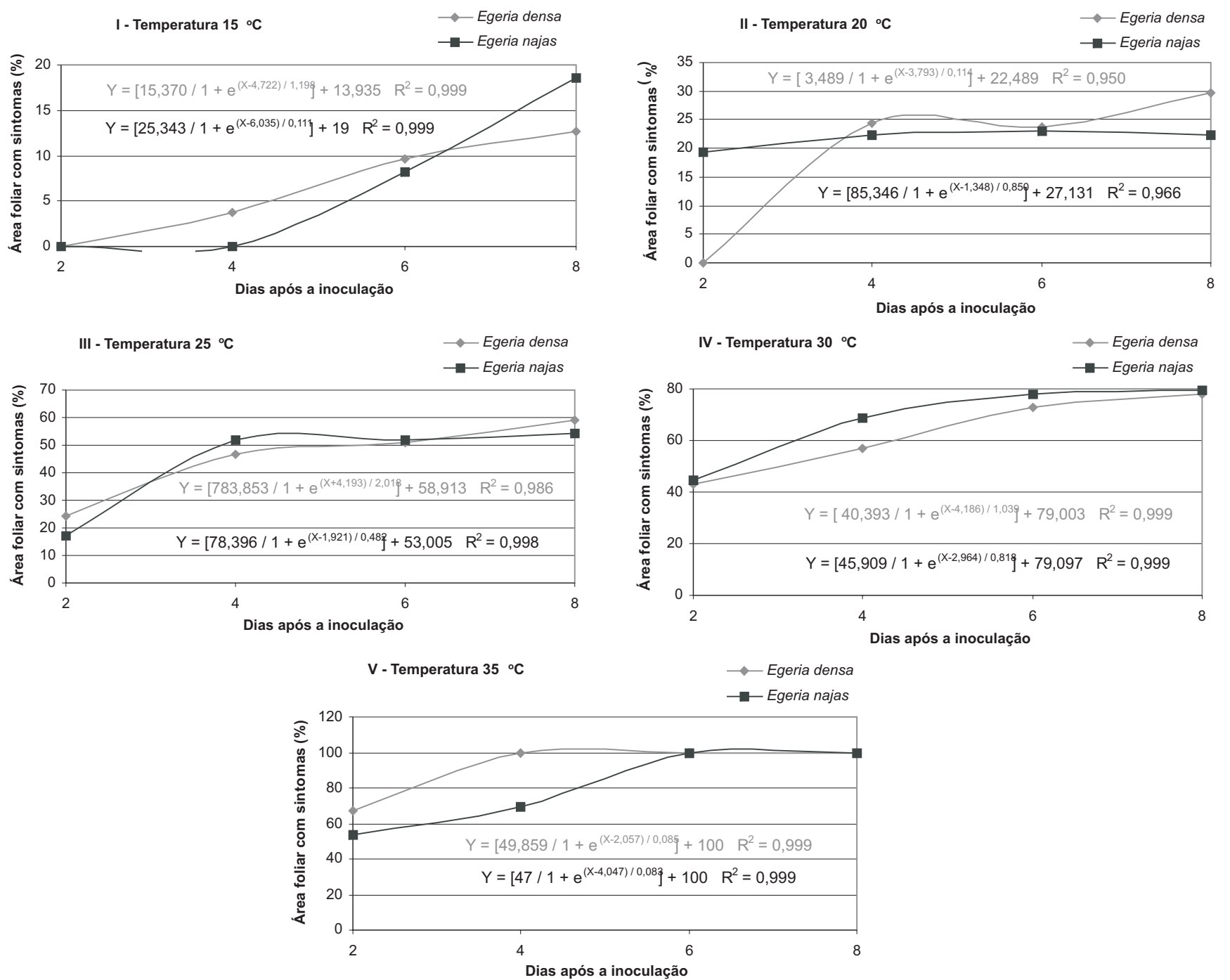

FIG. 2 - Curvas de progresso da doença causada por Fusarium graminearum em plantas de Egeria densa e de Egeria najas nas temperaturas de $15^{\circ} \mathrm{C}$ (I), $20^{\circ} \mathrm{C}$ (II), $25^{\circ} \mathrm{C}$ (III), $30^{\circ} \mathrm{C}$ (IV) e $35^{\circ} \mathrm{C}$ (V).

fresca (Figura 3 - I e II) apesar da presença do patógeno.

Temperatura: As plantas de E. densa, na presença do fungo, apresentaram menor produção de massa fresca quando submetidas às temperaturas de $15^{\circ} \mathrm{C}$ e $20^{\circ} \mathrm{C}$ (Figura 4 - I), nas temperaturas de 25,30 e $35^{\circ} \mathrm{C}$, não foi constatado o crescimento vegetativo (Figura 4 - I). Analisando as testemunhas dessa mesma espécie, observa-se que a única temperatura na qual não ocorreu ganho de massa fresca foi a de $35^{\circ} \mathrm{C}$. Com relação à E. najas, não houve ganho de massa fresca nas temperaturas mais elevadas $\left(30^{\circ} \mathrm{C}, 35^{\circ} \mathrm{C}\right)$, nos tratamentos inoculados com o patógeno (Figura 4 - II).

Os resultados observados mostram que os menores ganhos de massa fresca ocorreram devido à presença do patógeno, apesar de terem sido constatados também na ausência do fungo, em condições de temperatura elevada $\left(35^{\circ} \mathrm{C}\right.$ para $E$. densa). O crescimento de $E$. densa foi paralisado a partir de $25^{\circ} \mathrm{C}$ (Figura 4 - I) e de E. najas a partir de $30{ }^{\circ} \mathrm{C}$ (Figura 4 - II), na presença de $F$. graminearum.
O fotoperíodo e a temperatura ideais para o máximo desenvolvimento de doença podem variar dependendo do patossistema, segundo Allen et al. (1983). Conforme citado por Baensch \& Riel (1993), E. densa e E. najas não estão classificadas como plantas de aquário que necessitam de intensa luminosidade para seu desenvolvimento. Leung (2003) cita a temperatura, luminosidade, velocidade da corrente d'água, turbulência e profundidade como principais fatores físicos limitantes ao crescimento de macrófitas.

No presente ensaio as variações no fotoperíodo influenciaram, significativamente, no desenvolvimento das plantas tanto nos tratamentos inoculados como nas testemunhas não inoculadas. Nos tratamentos com fotoperíodos iguais ou superiores a $8 \mathrm{~h}$ diárias de luz, foram observadas menores severidades de doença. Este comportamento pode ser atribuído a maior atividade fotossintética das plantas e conseqüente menor atividade do fungo na presença de luz.

Nachtigal (2000) verificou que a atividade herbicida de F. graminearum se processou devido à produção contínua 
Influência do fotoperíodo e da temperatura na intensidade de doença...
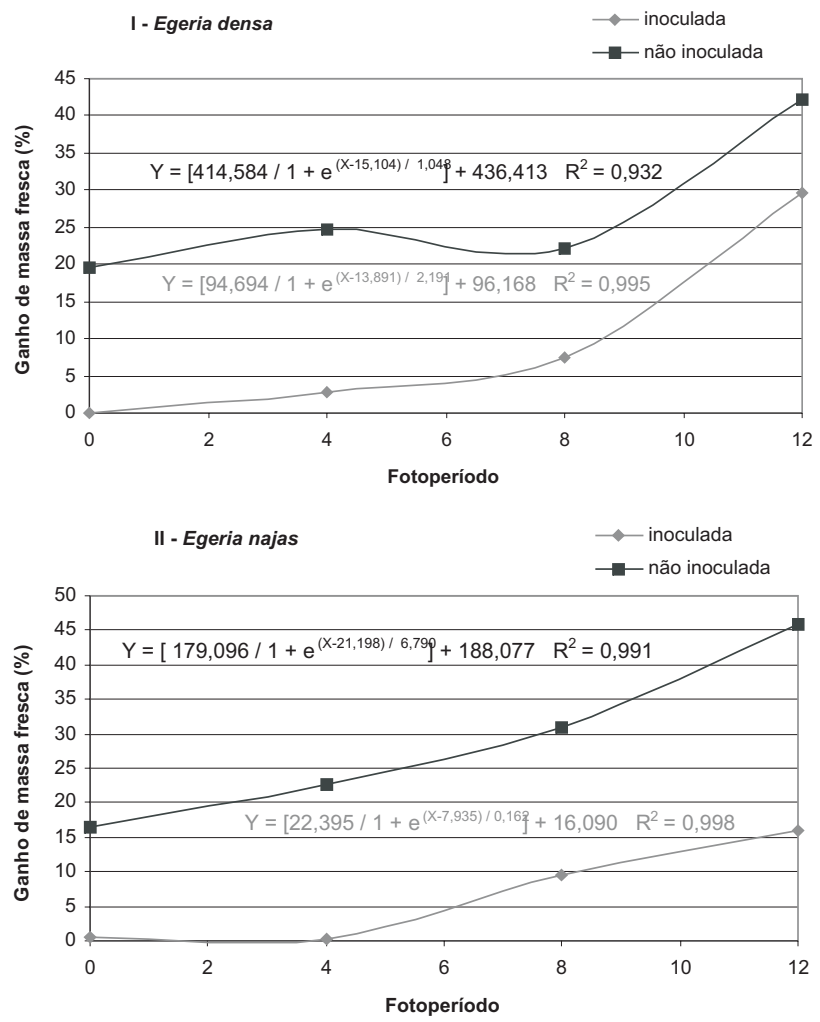

FIG. 3 - Efeito do fotoperíodo sobre o crescimento de plantas de Egeria densa (I) e E. najas (II), avaliadas pelo incremento de massa fresca e inoculadas com Fusarium graminearum, isolado FCAV\#940.
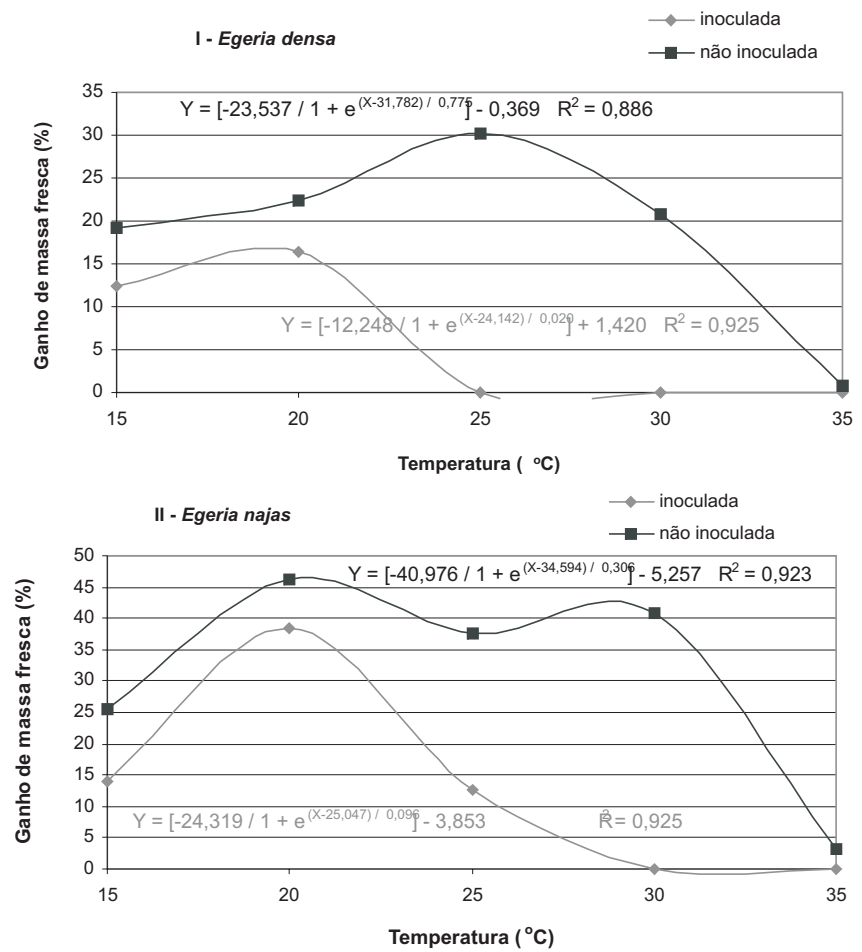

FIG. 4 - Efeito da temperatura sobre o crescimento de plantas de Egeria densa (I) e E. najas (II), avaliadas pelo incremento de massa fresca e inoculadas com Fusarium graminearum, isolado FCAV\#940. de micélio a partir de partículas inoculativas (micélio e conídios), bem como a liberação de metabólitos tóxicos produzidos pelo fungo e estabilizados pelos componentes do substrato (arroz).

Os resultados obtidos com variações de temperatura corroboram os apresentados por Nachtigal (2000), que observou aumento considerável na severidade de doença com temperaturas de $15^{\circ} \mathrm{C}$ e $20^{\circ} \mathrm{C}$. No presente experimento, contudo, os aumentos de severidade foram mais expressivos nos tratamentos de 20,25 e $30^{\circ} \mathrm{C}$. Observou-se maior sensibilidade de E. densa às temperaturas mais altas, resultando em aumento da senescência induzida, expressa por clorose generalizada dos tecidos.

Apesar do gênero Egeria ser nativo da América do Sul (St. John, 1961; Kissman, 1991), as espécies E. densa e E. najas podem ser encontradas crescendo em locais diversos, com distribuição geográfica diferenciada provavelmente devido às condições da temperatura ambiente. As plantas de E. densa desenvolvem-se melhor em temperaturas de 20 a $24^{\circ} \mathrm{C}$, enquanto que plantas de $E$. najas necessitam de temperaturas mais altas (23 a $27{ }^{\circ} \mathrm{C}$ ) para seu bom desenvolvimento (Baensch \& Riel, 1993). Este fato pode explicar, em parte, a maior sensibilidade de E. densa ao fungo, em temperaturas altas.

As informações aqui obtidas poderão auxiliar na interpretação de dados relacionados ao modo de ação do fungo e na identificação das variáveis que, uma vez alteradas, poderão contribuir para maior eficiência deste organismo como agente de biocontrole.

\section{REFERÊNCIAS BIBLIOGRÁFICAS}

ALLEN, S.J., BROWN, J.F. \& KOCHMAN, S.L. Effects of temperature, dew period and light on the growth and development of Alternaria helianthi. Phytopathology 73:839-6. 1983.

ANDERSON, L.W.J. Can Egeria densa be eradicated? Yes, but is it worth it?. Annual Meeting of Aquatic Plant Management Society, Memphis. Abstracts, 1998, p.18.

BAENSCH, H.A. \& RIEL, R. Aquarium Atlas. Vol. 2. 1993.

BLACKBURN, R.D., SUTTON, D.L. \& TAYLOR, T. Biological control of aquatic weeds. Journal of Irrigation and Draining. 97:42132. 1971.

BOYD, C.E. Vascular aquatic plants for mineral nutrient removal from polluted waters. Economic Botany 24:95-103. 1970.

CLARK, R.B. Characterization of phosphate of intact maize roots. Journal of Agriculture, Food and Chemistry 23:458-460. 1975.

CORRELL, D.S. \& CORRELL, H.B. Aquatic and wetland plants of southwestern United States. Stanford: Stanford University Press, v.1. 1975. pp.1-15.

KISSMAN, K.G. Plantas Infestantes e Nocivas. Tomo 1. São Paulo. BASF Brasileira S.A. 1991.

LEUNG, R. Detectando os fatores ambientais controladores da distribuição de macrófitas aquáticas. II Workshop de Macrófitas Aquáticas, Campo Grande. Resumos 2003.

LORENZI, H. Plantas daninhas do Brasil: Terrestres, aquáticas, parasitas, e tóxicas. 3nd ed. Instituto Plantarum de Estudos da Flora 


\section{C.R. Borges Neto et al.}

Ltda., Nova Odessa, SP. 2000.

MCKINNEY, H.H. Influence of soil temperature and moisture on infection of wheat seedlings by Helminthosporium sativum. Journal of Agricultural Research 26:194-218. 1923.

MENDES, D. Efeitos de herbicidas sobre alguns aspectos biológicos de Fusarium graminearum Schwabe (isolado FCAV\#940), agente potencial de controle biológico de Egeria densa e Egeria najas Planch. (Dissertação de Mestrado). Jaboticabal, FCAV/UNESP, 2002.

NACHTIGAL, G.F. Desenvolvimento de agente de controle biológico microbiano de Egeria densa e Egeria najas Planch. (Tese de Doutorado). Jaboticabal, FCAV/UNESP. 2000.

ROGERS, H.H. \& DAVIS, D.E. Nutrient removal by waterhyacinth.
Weed Science 20:423-7. 1972.

SHEARER, J.F. Development of a fungal pathogen for biocontrol of the submersed aquatic macrophyte $H y$ drilla verticillata. International Symposium on Biological Control of Weeds, 9, Stellenbosch. Proceedings... 1996. pp.473-7.

ST. JOHN, H. Monograph of the genus Egeria Planchon. Darwiniana 12:293-307. 1961

STEWARD, K.K. Nutrient removal potential of various aquatic plants. Hyacinth Control Journal 8:34-5. 1970.

TANAKA, R.H. Prejuízos provocados pelas plantas aquáticas. Workshop Sobre Controle de Plantas Aquáticas, Brasília. Resumos, 1998, pp.36-8. 